\title{
DA PLURALIDADE À SINGULARIDADE: PRESSUPOSTOS TEÓRICOS PARA UMA BIOÉTICA EM RICEUUR
}

\author{
From pluralism to singularity: theoretical assumptions for \\ bioethics in Ricœur's views
}

De la pluralidad a la singularidad: presupuestos teóricos para una bioética en Ricœur

Paulo Gilberto Gubert ${ }^{1}$

Universidade Católica de Pelotas, Pelotas, RS, Brasil. Marcelo Bonhemberger ${ }^{2}$ Pontifícia Universidade Católica do Rio Grande do Sul, Porto Alegre, RS, Brasil.

\section{Resumo}

O pensamento filosófico na atualidade é caracterizado pela diversidade e pela pluralidade, o que permite interpretações singulares acerca do julgamento moral, como no caso da bioética. Considerando a especificidade das interpretações, o propósito deste artigo é apresentar pressupostos para pensar a bioética a partir da filosofia

1 Doutor em Filosofia pela Universidade Federal de Santa Maria (UFSM). Professor do Instituto Superior de Formação Humanística da Universidade Católica de Pelotas (UCPel), Pelotas, RS, Brasil. http://orcid.org/oooo-0002-6443-4479. E-mail: gilbertogubert@gmail.com

2 Doutor em Filosofia pela Universidade Pontifícia Salesiana de Roma. Professor da Escola de Humanidades da Pontifícia Universidade Católica do Rio Grande do Sul (PUCRS), Porto Alegre, RS, Brasil. http://orcid.org/o000-0002-1295-3015. E-mail: mbonhemberger@gmail.com 
de Ricœur. Embora o filósofo tenha procurado elaborar uma ética, a bioética esteve sempre em seu horizonte, sendo designada ou de forma fragmentária, pelo conceito de éticas regionais, ou de forma robusta, como sabedoria prática.

Palavras-chave: Ricœur. Bioética. Éticas regionais. Sabedoria prática.

\begin{abstract}
Today's philosophical thought is characterized by diversity and pluralism. This enables unique interpretations on moral judgment, such as in bioethics. In view of the specific nature of interpretations, the purpose of this article is to present some theoretical assumptions to look at bioethics from the perspective of Ricœur's philosophical views. Although he sought to develop an ethics, he has also been interested in addressing bioethics. It has always been guided, sometimes in part, by the concept of regional ethics, or in a comprehensive way, as practical wisdom.
\end{abstract}

Keywords: Ricœur. Bioethics. Regional ethics. Practical wisdom.

\title{
Resumen
}

El pensamiento filosófico en la actualidad se caracteriza por la diversidad y la pluralidad, lo que permite interpretaciones singulares sobre el juicio moral, como en el caso de la bioética. Teniendo en cuenta la especificidad de las interpretaciones, el propósito de este artículo es presentar los presupuestos para pensar la Bioética desde la filosofía de Ricoeur. Aunque el filósofo ha intentado elaborar una ética, la bioética estuvo siempre en su horizonte, siendo designada o fragmentariamente, por el concepto de éticas regionales, o sólida, como sabiduría práctica.

Palabras clave: Ricœur. Bioética. Éticas regionales. Sabiduría práctica.

\section{Introdução}

Ricœur sempre manteve presente em seu horizonte de pensamento as questões referentes à ética e à justiça, muito embora tenha sido a partir dos anos 1980 que ele passou a escrever sistematicamente a respeito dessas temáticas. Ademais, ele não foi um bioeticista, isto é, alguém que 
se debruçou exclusivamente sobre esse assunto. No entanto, o seu pensamento permite aportar significativas contribuições ao campo da bioética.

Para situar a discussão em torno do movimento de pensamento que convergiu para a bioética, no decorrer do século XX, em especial nos Estados Unidos, será preciso situar, brevemente, as origens da bioética, bem como alguns de seus principais expoentes no âmbito filosófico.

A palavra "bioética" (bio-ethik) foi cunhada pelo pastor Fritz Jahr em um periódico alemão chamado Kosmos (JAHR, 1927). Esse autor referiu-se a um "imperativo bioético" tendo como base teórica o imperativo Kantiano, ampliando o campo da ética para todos os seres vivos, incluindo os animais e as plantas (MUZUR; SASS, 2012; 2017). O nome de Fritz Jahr foi mencionado pela primeira vez em 1997, em uma conferência em Tübingen, pelo professor Rolf Lother, da Universidade Humboldt. Posteriormente, tornou-se conhecido pelo filósofo Hans-Martin Sass, que traduziu para o inglês o seu artigo em 2007 (SASS, 2008).

O termo Bioethics, no entanto, tornou-se conhecido pela proposta do oncologista Van Rensselaer Potter na década de 1970, em seu artigo "Bioethics: The Science of Survival" (POTTER, 1970) e em sua obra Bioethics: Bridge to the Future (POTTER, 1971). Essa nova terminologia recebeu diversas matizes, permitindo a abordagem da bioética no plural (bioéticas). Sua origem deriva de um duplo fenômeno: por um lado, a revolução biomédica; por outro, a crise da ética universal. O bioquímico americano, no início, pensou a bioética como uma ponte entre a ciência biológica e as humanidades e, posteriormente, introduziu novos elementos: a bioética global e profunda, combinando competência interdisciplinar, humildade e responsabilidade para com as futuras gerações (POTTER, 1988; PESSINI, SGANZERLA; ZANELLA, 2018).

Em busca de uma compreensão do conceito de bioética, importa consultar uma das obras referenciais dessa temática, a Encyclopedia of 
Bioethics ${ }^{3}$, que a conceitua como um neologismo originário dos conceitos bios (vida) e ethike (ética) e a define "como um estudo sistemático das dimensões morais - incluindo visão, decisão, conduta e normas morais - das ciências da vida e do cuidado da saúde, utilizando uma variedade de metodologias éticas, em contexto interdisciplinar" (REICH, 1995, p. $\mathrm{XXI}$ ). A originalidade dessa problemática surge com o desenvolvimento da ciência biomédica e sua aplicação, uma vez que novas questões metodológicas aparecem: como resolver e enfrentar esses novos desafios? Como regular novas práticas e procedimentos em ausência de normas específicas? A ideia amadureceu para que os problemas postos pelos novos desafios das ciências biomédicas fossem afrontados mediante a aplicação de princípios ou regras gerais aos casos singulares.

Sob a ótica do professor italiano Merlo (2011), a bioética pode ser pensada como ética aplicada quando se remete à orientação metodológica de caráter dedutivo, baseada em princípios ou normas de aplicação aos casos concretos. As questões seriam individualizadas e enfrentadas com base em um ou mais critérios normativos, determinando a conduta moralmente mais justificada. A dinâmica de deliberações e justificações dos juízos morais é delineada de forma articulada. Os juízos particulares encontram sua justificação nas normas; as normas, por sua vez, encontram isso nos princípios de natureza geral ou universal, e os princípios, nas teorias éticas. Frankena (1981), por sua vez, aponta a beneficência e a justiça como dois princípios de moralidade a serem observados como deveres prima facie.

Posteriores desdobramentos e aplicações deu-se com o Belmont Report, elaborado pela Comissão Nacional Americana, quando filósofos e teólogos foram requisitados para ajudar na elaboração de princípios éticos básicos para orientar a pesquisa com seres humanos. Essa comissão emitiu, após quatro anos de trabalho, um documento que causou impacto

\footnotetext{
3 Nota-se que na Encyclopedia of Bioethics, a partir da $4 .^{a}$ edição, o título passou a ser denominado apenas de Bioética (Bioethics), na introdução, o filósofo Bruce Jennings, da universidade de Yale, editor-chefe, aduz o reconhecimento em relação à bioética global e a importância do rigor interdisciplinar.
} 
importante na comunidade médico-científica, tornando-se a declaração principialista clássica para a ética ligada à pesquisa com seres humanos. Os três princípios propostos no Relatório Belmont foram: o respeito às pessoas, a beneficência e a justiça. No contexto da pesquisa com seres humanos, esses três princípios abrem o caminho, respectivamente, aos requisitos do consentimento informado, à avaliação dos riscos e benefícios e à equidade na seleção dos participantes de pesquisa (JONSEN, 1998).

O notável volume de Tom L. Beauchamp (que fazia parte da comissão) e James F. Childress, com o título Principles of Biomedical Ethics (2012), mais tarde distinguiu os princípios de beneficência e não maleficência. De acordo com essa doutrina, a bioética passou a centrar-se em alguns princípios (autonomia, beneficência, não maleficência e justiça), esse modelo foi denominado de principialismo. O principal conteúdo do volume diz respeito ao sentido, ao alcance dos princípios e sobre seu funcionamento em análises de casos (BEAUCHAMP; CHILDRESS, 2012). Essa teoria não se baseia em nenhuma corrente filosófica claramente articulada.

Ulteriormente, na década de 1980, surgiu a obra de Engelhardt (2013), que propõe uma ética para os "estranhos morais" (moral strangers), abrindo caminho novo para a ética médica. Nesse caso, quando a discussão acontece entre "amigos morais" (moral friends), a resolução das controvérsias não é aparente, mas em determinado contexto, os casos exemplares podem ser facilmente reconhecidos e aplicados. Essa forma de resolver os casos encontra dificuldade ao nos depararmos como estranhos morais (ENGELHARDT, 2013).

Dentre as várias características da bioética, o pluralismo, enfatizado pelo bioeticista texano, destaca-se pela utilização de alguns princípios que tem como intuito auxiliar nas situações problemáticas impostas pelo constante progresso da biotecnologia. Engelhardt (2012), médico e filósofo, articula o princípio de permissão (principle of permission) como possibilidade de resoluções de divergências morais, uma vez que a tentativa de fundamentar uma bioética dotada de conteúdo (content-full morality), não obteve sucesso. A bioética secular consegue fornecer apenas alguns princípios formais diante 
do pluralismo moral e a diversidade de crenças. Por isso, para ele, a ética deve buscar a intersubjetividade, guiada pelo princípio mínimo de permissão, que é fonte de autoridade moral. Para Engelhardt (2012), a bioética é um quebra-cabeças, formada por controvérsias e visões plurais acerca da natureza das questões normativas. Dentro desta ótica, Hottois reitera a ideia de uma bioética secular, plural e multidisciplinar (HOTTOIS, 2015).

Um modelo apropriado que reconheça a variedade e o caráter de conflitos morais exige uma percepção adequada, de maneira que se determine como aplicá-los na resolução de controvérsias relativas aos casos particulares. Assim, "nenhuma explicação secular geral pode determinar o sentido moral que torna o discernimento certo ou errado, sem forçar a questão" (ENGELHARDT, 2013, p. 70). Será necessário ter uma visão do bem para poder avaliar as consequências. Porém, fora de qualquer tradição particular do bem, será difícil discernir qual decisão vai ser a mais correta a ser aplicada, porquanto, conforme salienta Hanson (2009), é difícil justificar uma moral particular no contexto social permeado pela pluralidade. As pessoas podem discordar a respeito de qual seria a solução mais apropriada referente aos problemas morais.

Com base nesse contexto, no qual foram acentuadas as características fundamentais da bioética, especialmente no que diz respeito à sua pluralidade e interdisciplinaridade, pretende-se apresentar alguns pontos centrais da "pequena ética" de Ricœur enquanto pressupostos para entender a bioética a partir do pensamento desse autor. O problema é que, conforme mencionado acima, o filósofo francês não escreve especificamente nenhum texto sobre bioética. O fato de a temática em questão não ser central em seu pensamento implica em um trabalho de "garimpo" do conceito em seus textos sobre ética, justiça, política, antropologia e éticas regionais (médica, judiciária, dentre outras). Nesse ponto, uma questão essencial para entender o pensamento de Ricœur precisa ser esclarecida: como contemplar a pluralidade de éticas sem desrespeitar a univocidade da norma? O deslinde da questão é nosso objeto de investigação neste artigo. 


\title{
1 A bioética no arcabouço da pequena ética
}

No livro O justo 2: justiça e verdade e outros estudos, Ricœur (2008) publicou o texto "Da moral à ética e às éticas", no qual enfatiza a centralidade da moral kantiana em sua ética, bem como a crítica que subjaz ao projeto universalista kantiano: a aplicabilidade. $O$ filósofo francês entende que a moral kantiana tem por função

\begin{abstract}
designar, por um lado, a região das normas, em outras palavras, princípios do permitido e do proibido, e, por outro, o sentimento de obrigação como face subjetiva da relação de um sujeito com normas. Na minha opinião, aí está o ponto fixo, o cerne da questão. E é em relação a ele que se deve fixar um emprego para o termo ética. Vejo então o conceito de ética partir-se em dois: um ramo designa algo como o que está a montante das normas - falarei então de ética anterior - e outro ramo designa algo que está como que a jusante das normas - e falarei então de ética posterior (RICÆEUR, 2008, p. 49).
\end{abstract}

A ética anterior situa-se nos limites da teleologia de Aristóteles (1984). A ética posterior, por sua vez, é a ética aplicada - ou sabedoria prática - que corresponde ao domínio das "éticas regionais", porque se distribui por "regiões", isto é, entre muitos campos de aplicação, tais como a ética jurídica, a ética dos negócios, a ética do meio ambiente e a ética médica. Isso implica em considerar que a bioética, na obra de Ricœur, está alicerçada nos conceitos de ética (finalidade), de moral (fundamento) e, mormente, de sabedoria prática (convicção).

O principal referencial teórico para a investigação desses conceitos é o livro Soi-même comme un autre (1990a), mais especificamente os estudos - ou capítulos - sétimo, oitavo e nono. Esses estudos demarcam a elaboração mais sistemática e completa da ética ricœuriana, denominada 
pequena ética4. Muito embora Ricœur considere sua ética pequena, por aparentemente dedicar-lhe tão somente três capítulos de um livro, a questão é central no pensamento do autor, uma vez que é abordada em muitos de seus livros e em inúmeros artigos 5 .

A ética ricœuriana transita entre a teleologia e a deontologia, mas é testada nos conflitos do cotidiano, quando do julgamento moral em situação, por meio do qual a convicção torna-se sabedoria prática. Nesse sentido, a distinção entre ética e moral, convencionada pelo autor, trata a ética enquanto visada - intenção, perspectiva - de uma vida concluída e a moral enquanto articulação dessa visada em normas (RICCEUR, 1990a; DA RE, 1993). Para o filósofo, nesse ponto, distinguem-se claramente os legados aristotélico e kantiano: "uma herança aristotélica, na qual a ética é caracterizada pela perspectiva teleológica, e uma herança kantiana, em que a moral é definida pelo caráter de obrigação da norma, portanto, por um ponto de vista deontológico" (RICÆEUR, 1990a, p. 200, tradução nossa, grifos do autor) ${ }^{6}$. Uma vez definidos esses conceitos, ele propõe um esquema tripartido para sua visada ética: trata-se da "visada da 'vida boa', com e para outros, nas instituições justas" (RICÆFUR, 1990a, p. 202, tradução nossa, grifos do autor).?

Diante desse contexto, Ricœur considera como fundamental para a pequena ética a não permanência na ortodoxia dos textos de Aristóteles e de Kant. Inicialmente, o autor enuncia que há um primado da visada ética aristotélica sobre a norma moral kantiana. Em um segundo momento, é a

\footnotetext{
4 Trata-se, segundo Ricœur (LECOMTE, 1996, p. 4) de "une 'petit éthique' qui couronne l'exploration des pouvoirs qui font de l'homme un être 'capable'”.

5 A atenção destinada por Ricœur às questões de ética e de moral aparece nos livros: Le juste II, La nature et la règle, Lectures 1, De la métaphysique à la morale, Du texte à l'action e La mémoire, l'histoire, l'oublie; e nos artigos: Sympathie et respect: phénoménologie et éthique de la seconde personne, The Problem of the Foundation of Moral Philosophy, Éthique et Morale e De la morale à l'éthique et aux éthiques. Não obstante tenhamos mencionado esses livros e artigos, existem muitos outros textos - especialmente entrevistas transcritas e artigos - nas quais o autor retoma as questões fundamentais da Ética.

6 Do original: Un héritage aristotélicien, où l'éthique est caractérisée par sa perspective téléologique, et un héritage kantien, où la morale est définie par le caractère d'obligation de la norme, donc par un point de vue déontologique.
}

7 Do original: Visée de la 'vie bonne' avec et pour autrui dans des institutions justes. 
ética que deve passar pelo crivo da norma. Por último, ele aponta para a sabedoria prática enquanto possibilidade de fazer frente à singularidade dos inevitáveis conflitos do cotidiano, aos quais a ética e a moral nem sempre conseguem oferecer uma resposta satisfatória (MORATALLA, 2007).

Isso ocorre porque a passagem da visada ética pelo crivo da norma moral não resolve uma questão fundamental, visto que se trata dos conflitos suscitados pelos casos difíceis, que exigem capacidade de inventividade e de produção de sentido, isto é, de juízo reflexivo. Nesse ponto, Ricœur (2008) reafirma, na esteira de Kant, a diferença entre juízo determinante e juízo reflexivo. O primeiro é aquele no qual se conhece melhor a regra do que sua aplicação. O segundo é aquele no qual se conhece mais o caso do que a regra, o que não permite que a regra seja aplicada de forma automática.

Em outros textos de Ricœur, o juízo reflexivo será chamado de julgamento prudencial, que caracteriza a sabedoria prática. Esta não significa uma terceira instância, para além da ética e da moral, pois sua função consiste em demonstrar que - muito embora nossas práticas sejam guiadas pelos princípios da moralidade - existem situações nas quais a moral da obrigação - em virtude de ter como prática a submissão de um caso particular a uma regra - entra em aporias que somente poderão ser resolvidas após o retorno à intuição primeira da ética.

\section{Deliberar bem: a sabedoria prática}

O capítulo nove de Soi-même comme un autre, intitulado "Le soi et la sagesse pratique: la conviction", é introduzido por meio de um interlúdio, no qual Ricœur (1990a) apresenta uma leitura crítica da peça teatral Antígona, de Sófocles (2011). Ele entende que a peça Antígona demonstra a imprudência de Creonte, que não ouviu ninguém, nem o desesperado Hemon nem mesmo a sabedoria de Tirésias. Creonte julgou o caso individualmente, deliberou mal e foi injusto em sua decisão, que culminou em tragédia. Isso significa, para Ricœur (2011, p. 14), que "os conflitos 
ocorrem precisamente no momento em que caracteres obstinados e inflexíveis se identificam tão completamente com uma regra particular que se tornam cegos para quaisquer outras".

Ademais, o autor procura demonstrar que a "transição da catarse à convicção consiste, essencialmente, em uma meditação sobre o lugar inevitável do conflito na vida moral" (RICEUR, 1990a, p. 288, tradução nossa, grifo do autor) ${ }^{8}$. Nesse contexto, a tragédia pode ser comparada às experiências-limite vividas no cotidiano, uma vez que ambas são geradoras de aporias.

A leitura que Ricœur propõe acerca da Antígona aponta para a necessidade de a convicção estar alicerçada na sabedoria para tomar as decisões corretas e justas e, consequentemente, deliberar bem. Porém, a instrução pelo trágico não denota um aprendizado moral, muito embora duas lições possam ser aprendidas. Primeiro, que o conflito é inevitável; segundo, que o trágico abre o caminho para o momento da convicção, que está para além da catarse. Nesse sentido, Ricœur (1990a, p. 288) entende que "a tragédia, após ter desorientado o olhar, condena o homem da práxis a reorientar a ação por sua própria conta e risco, no sentido de uma sabedoria prática em situação que responda melhor à sabedoria trágica" (tradução nossa). ${ }^{9}$

O filósofo assinala que a inevitabilidade do conflito reporta ao conceito kantiano de respeito. Para Kant (2007, p. 32),

aquilo que eu reconheço imediatamente como lei para mim, reconheço-o com um sentimento de respeito que não significa senão a consciência da subordinação da minha vontade a uma lei, sem intervenção de outras influências sobre a minha sensibilidade [...]. O objeto do respeito é portanto simplesmente a lei, quero dizer aquela lei que nos impomos

\footnotetext{
8 Do original: Transition de la catharsis à la conviction consiste pour l'essentiel dans une méditation sur la place inévitable du conflit dans la vie morale.

9 Do original: La tragédie, après avoir désorienté le regard, condamne l'homme de la praxis à réorienter l'action, à ses propres risques et frais, dans le sens d'une sagesse pratique en situation qui réponde le mieux à la sagesse tragique.
} 
a nós mesmos, e no entanto como necessária em si. Como lei que é, estamos-lhe subordinados (grifos do autor).

No conceito de respeito, o filósofo francês identifica duas vertentes que se dividem na interpretação do imperativo categórico, a saber, a universalista e a pluralista: "a vertente universalista do imperativo, simbolizada pela ideia de humanidade, e a vertente que podemos dizer pluralista, simbolizada pela ideia de pessoas como fins em si mesmas" (RICEFUR, 1990a, p. 305, tradução nossa) ${ }^{10}$. Para ele, não se tratam de vertentes em oposição, pois "a humanidade designa a dignidade como aquilo pelo que as pessoas são respeitáveis, a despeito - ousamos dizer de sua pluralidade" (RICEUR, 2014, p. 303, grifo do autor). Sendo assim, Kant (2007) não dá lugar ao conflito, visto que somente a universalidade da regra deverá reger as máximas que, por sua vez, coordenam as ações.

Entretanto, é justamente nesse ponto que se apresenta a possibilidade do conflito. De acordo com Ricœur, a alteridade concernente à ideia de pluralidade, em determinadas circunstâncias, entra em descompasso com o universalismo das regras inerentes à ideia de humanidade. Isso significa que "o respeito tende então a se cindir em respeito da lei e respeito das pessoas. Nessas condições, a sabedoria prática pode consistir em dar a prioridade ao respeito das pessoas, em nome da solicitude dirigida às pessoas em sua singularidade insubstituível" (1990a, p. 305, tradução nossa)." Portanto, o conflito surge na aplicação das máximas às situações concretas, pois é nesse momento que a alteridade de cada pessoa deve ser reconhecida.

Nesse sentido, a segunda formulação do imperativo categórico, ao considerar o sujeito como fim em si mesmo - com base na ideia de humanidade -, traz à tona um problema. Ricœur (1990a, p. 308, tradução

\footnotetext{
10 Do original: Le versant universaliste de l'impératif, figuré par l'idée d'humanité, et le versant qu'on peut dire pluraliste, figuré par l'idée des personnes comme des fins en elles-mêmes.

1 Do original: Le respect tend alors à se scinder en respect de la loi et respect des personnes. La sagesse pratique peut dans ces conditions consister à donner la priorité au respect des personnes, au nom même de la sollicitude qui s'adresse aux personnes dans leur singularité irremplaçable.
} 
nossa) considera que se trata de uma limitação, na medida em que o trajeto de aplicação da norma moral desconsidera as

situações singulares, em que o outro se ergue em sua singularidade insubstituível [...]. A consideração das pessoas como fins em si mesmas introduz um fator novo, potencialmente discordante, com relação à ideia de humanidade, a qual limita-se a prolongar a universalidade na pluralidade em detrimento da alteridade ${ }^{12}$.

Para Ricœur, o núcleo dessa discussão pode ser atingido a partir da questão da falsa promessa, conforme enunciada por Kant (2007, p. 33), na Fundamentação da metafísica dos costumes: "não posso eu, quando me encontro em apuro, fazer uma promessa com a intenção de a não cumprir?" No mesmo texto, ele condena a falsa promessa, propondo duas novas questões:

ficaria eu satisfeito de ver a minha máxima (de me tirar de apuros por meio de uma promessa não verdadeira) tomar o valor de lei universal (tanto para mim como para os outros)? E poderia eu dizer a mim mesmo: - Toda a gente pode fazer uma promessa mentirosa quando se acha numa dificuldade de que não pode sair de outra maneira? Em breve reconheço que posso em verdade querer a mentira, mas que não posso querer uma lei universal de mentir; pois, segundo uma tal lei, não poderia propriamente haver já promessa alguma, porque seria inútil afirmar a minha vontade relativamente às minhas futuras ações a pessoas que não acreditariam na minha afirmação, ou, se precipitadamente o fizessem, me pagariam na mesma moeda. Por conseguinte, a minha máxima, uma vez arvorada em lei universal, destruir-se-ia a si mesma necessariamente (KANT, 2007, p. 34).

\footnotetext{
12 Do original: Situations singulières, où autrui se dresse dans sa singularité irremplaçable [...] La considération des personnes comme des fins en elles-mêmes introduit un facteur nouveau, potentiellement discordant, par rapport à l'idée d'humanité, laquelle se borne à prolonger l'universalité dans la pluralité au détriment de l'altérité.
} 
Ricœur assinala que aqui se apresenta mais claramente o tom discordante entre humanidade e alteridade. Na censura kantiana à falsa promessa - porque ela está em desacordo com a lei universal do imperativo - o outro, isto é, aquele que efetivamente poderia vir a ser prejudicado ou beneficiado, não parece ser realmente tomado em consideração, uma vez que é toda a humanidade, e não precisamente o outro que foi ferido por uma falsa promessa. Nesse sentido, a falsa promessa é uma forma de violência situada no uso da linguagem. De acordo com Ricœur (1990a, p. 308, tradução nossa), "não é antes a integridade pessoal que está em jogo nos ditos deveres para com os outros? Não é o si mesmo que se despreza ao pronunciar um falso juramento?"13.

Da preocupação com a integridade pessoal resulta, para Ricœur (1990a, p. 309, tradução nossa), a necessidade do recurso à Regra de Ouro, "na medida em que esta leva em conta a dissimetria inicial entre o agente e o paciente, com todos os efeitos de violência derivados dessa dissimetria. Tratar outrem somente como um meio é já começar a lhe fazer violência"14.

A promessa autêntica, isto é, a promessa mantida, não pode ser vinculada tão somente a um ato de discurso, que o agente pode manter no plano da interlocução. Em cada promessa, há uma questão moral implícita e que traz consigo a razão pela qual é preciso manter-se fiel à palavra dada. A esse respeito, Ricœur (1990a, p. 309, tradução nossa) entende que "prometer é uma coisa. Ser obrigado a guardar suas promessas é outra. Chamamos de princípio de fidelidade a obrigação de cumprir as promessas"15.

O princípio de fidelidade envolve simultaneamente o indivíduo que promete e o destinatário da promessa, que obriga o primeiro a cumprir com

\footnotetext{
13 Do original: N'est-ce pas plutôt l'intégrité personnelle qui est en jeu dans les devoirs dits envers autrui? N'est-ce pas soi-même qu'on méprise en prononçant un faux serment?

14 Do original: Dans la mesure où celle-ci prend en compte la dissymétrie initiale de l'agent et du patient, avec tous les effets de violence ressortissant à cette dissymétrie. Traiter autrui seulement comme un moyen, c'est déjà commencer de lui faire violence.

15 Do original: Promettre est une chose. Etre obligé de tenir ses promesses en est une autre. Appelons principe de fidélité l'obligation de tenir ses promesses.
} 
o prometido. Isso significa que há uma confiança mútua anterior ao ato de discurso enunciado pela promessa. Essa confiança gera expectativa, que, por sua vez, exige engajamento. Nesse sentido, Ricœur, na esteira de G. Marcel, entende que engajamento significa uma resposta fiel ao outro que interpela o si. Nas palavras do próprio Marcel (1935), trata-se da "disponibilidade".

Ricœur (1990a, p. 312, tradução nossa) assinala ainda que, uma vez constatada "a cesura tão cuidadosamente ocultada por Kant entre o respeito pela regra e o respeito pelas pessoas"16, a disponibilidade é que permite o redirecionamento do imperativo categórico a uma abertura para a estrutura dialógica concernente à Regra de Ouro. Trata-se de uma estrutura que "precisa ser decomposta em estrutura diádica, ou dual, que põe em jogo duas pessoas - a que promete e a obrigatária com a qual a primeira se compromete" (RICEUR, 2014, p. 308).

O desvio do imperativo pela disponibilidade é necessário na medida em que o universalismo que rege as regras morais não leva em conta os contextos históricos e intersubjetivos de elaboração dessas regras. A ambição universalista da autonomia parte de um princípio que não é egológico, nem monológico, mas pré-dialógico. Sendo assim, o indivíduo autônomo, no qual se fundamenta a regra de reciprocidade, não pode mais ser considerado autossuficiente.

Segundo Ricœur, a autonomia é tributária da heteronomia, em um contexto em que o si autônomo passa a ser compreendido sob o enfoque da alteridade. Isso implica em considerar a relevância dos contextos históricos, no decurso da aplicação das máximas do imperativo às situações concretas, a fim de que a reciprocidade exigida pela promessa não seja responsável por dar início ao conflito. Por conta disso, o filósofo francês entende que,

se a fidelidade consiste em responder à expectativa do outro que conta comigo, é essa expectativa que devo tomar como medida da aplicação da regra [...]. A sabedoria prática consiste

16 Do original: La césure si soigneusement occultée par Kant entre le respect pour la règle et le respect pour les personnes. 
em inventar as condutas que mais satisfarão à exceção que requer a solicitude traindo o menos possível a regra (RICEUR, 1990a, p. 312, tradução nossa) ${ }^{17}$.

Existem situações que evidenciam o conflito entre as normas morais e as práticas do cotidiano - os casos difíceis - e que demonstram a aplicabilidade da sabedoria prática. Nesse sentido, para Ricœur (PELICIER; RICCEUR, 1994, p. 10), "aquilo a que os juristas chamam os hard cases, os casos difíceis, são aqueles em que não sabemos qual a regra para os enquadrar. É preciso inventar uma espécie de regra ad hoc". O filósofo francês menciona dois exemplos de hard cases que se referem, de um lado, ao caso da "vida acabando" e, de outro, da "vida começando".

No que concerne ao primeiro caso, trata-se do problema de dizer ou não dizer a verdade aos moribundos. Aparentemente estamos diante de um paradoxo, conforme enuncia Ricœur (1990a, p. 313, tradução nossa): "ou dizer a verdade, sem levar em conta a capacidade do moribundo de recebê-la, por puro respeito à lei que supostamente não tolera nenhuma exceção; ou mentir cientemente, por medo, consideramos, de enfraquecer no doente as forças que lutam contra a morte"18. Contudo, as polaridades opostas - que, de forma imediata - não resolvem o problema, podem oferecer alternativas - isto é, de forma mediata - para pensar uma solução adequada para o caso. Em outros termos, significa dizer que a sabedoria prática envolve criatividade, pois consiste "em inventar os comportamentos justos apropriados à singularidade dos casos" (RICEUR, 1990a, p. 313, tradução nossa) ${ }^{19}$.

\footnotetext{
17 Do original: Si la fidélité consiste à répondre à l'attente de l'autre qui compte sur moi, c'est cette attente que je dois prendre pour mesure de l'application de la règle [...]. La sagesse pratique consiste à inventer les conduites qui satisferont le plus à l'exception que demande la sollicitude en trahissant le moins possible la règle.

18 Do original: Ou bien dire la vérité sans tenir compte de la capacité du mourant à la recevoir, par pur respect de la loi supposée ne tolérer aucune exception; ou bien mentir sciemment, de peur, estime-t-on, d'affaiblir chez le malade les forces qui luttent contre le mort.

19 Do original: Inventer les comportements justes appropriés à la singularité des cas.
} 
A decisão refletida, que acompanha a sabedoria prática, nesse caso, traz à tona os conceitos de sofrimento e de felicidade. Sobre o primeiro, Ricœur (2013) reflete, no artigo "La souffrance n'est pas la douleur", com base na comparação entre a mediatez do cogito e a imediatez do sofrimento, sugerindo uma atualização da fórmula "Penso, logo existo", para "Eu sofro - eu sou". O autor menciona que não há aí um ergo, como no cogito, ergo sum. O caráter imediato é inevitável, pois não há espaço para uma dúvida metódica, como em Descartes. O cogito reduzido a um eu sofrente é, ele mesmo, uma ferida aberta.

Por outro lado, de acordo com o princípio teleológico, o autor considera a necessidade da vida feliz enquanto horizonte ético. A questão fundamental é que não se deve definir a felicidade como ausência de sofrimento, para que não se estabeleça uma mera inversão à regra de não mentir. Ricœur (1991, p. 315) entende que "a preocupação de não 'fazer sofrer' a nenhum preço os doentes no fim de sua vida termina por constituir como regra o dever de mentir aos moribundos. Nunca a sabedoria prática poderia consentir em transformar em regra a exceção à regra"20. Em determinadas ocasiões, falar a verdade não implica em condenar o moribundo à morte. Todavia, a questão será decidir o momento oportuno e saber dosar a verdade a ser dita.

Compreende-se assim que é preciso ter cuidado, em primeiro lugar, para com o outro que sofre e, desse modo, saber avaliar qual é a forma mais adequada de falar a verdade para o moribundo. A esse respeito, Ricœur (1990a, p. 313) menciona que "uma coisa é enunciar uma doença, outra é revelar o seu grau de gravidade e as poucas chances de sobrevida, outra ainda é desferir a verdade clínica como uma condenação à morte" (tradução nossa) ${ }^{21}$.

A regra que obriga a dizer a verdade, por sua vez, também não pode ter a primazia, porque corre o risco de tornar-se cega e indiferente à pes-

\footnotetext{
20 Do original: Le souci de ne 'faire souffrir' à aucun prix les malades au terme de leur vie aboutit à ériger en règle le devoir de mentir aux mourants. Jamais la sagesse pratique ne saurait consentir à transformer en règle l'exception à la règle.

${ }^{21}$ Do original: Une chose est de nommer la maladie, une autre d'en révéler le degré de gravité et le peu de chances de survie, une autre d'assener la vérité clinique comme une condamnation à mort.
} 
soa do outro, vulnerável e sofredor (RICEUR, 1990a; DOPPENSCHMITT, 2015). Para o filósofo francês, "neste caso, talvez seja preciso ter compaixão pelos seres muito fracos, moral e fisicamente, para entenderem a verdade" (RICCEUR, 1991, p. 313, tradução nossa) ${ }^{22}$. Por conseguinte, o que se verifica é a necessidade de sensibilizar-se, ser solícito e tornar-se próximo, procurando impedir que se aumente o sofrimento de alguém que já sofre em demasia (ROSSATO, 2010).

Ricœur (1955) apresenta uma distinção entre as noções de "próximo" e de socius no livro Histoire et vérité. Por um lado, partindo da análise da "Parábola do Bom Samaritano", o autor sugere que o próximo não se define por um conceito, e sim se torna presente por meio do encontro efetivo entre duas pessoas: uma em estado vulnerável e a outra solícita. Por outro lado, da sociologia emerge o conceito de socius enquanto sujeito que exerce uma função social, mediata - que não pode se tornar "próximo" da pessoa debilitada porque tem um compromisso social inadiável. Nesse contexto, o conceito de solicitude implica em uma relação de reciprocidade, pois ele se fundamenta na troca, em que o dar e o receber abarcam, simultaneamente, atividade e passividade. Trata-se de considerar "uma autêntica reciprocidade na troca, que, na hora da agonia, se refugia no murmúrio compartilhado das vozes ou no frágil aperto de mãos que se cumprimentam" (RICEUR, 2014, p. 210).

O segundo caso que implica no uso da sabedoria prática é o que diz respeito ao início da vida. Trata-se de uma problemática com um grau superior de complexidade, por envolver questões ontológicas que não estão presentes no caso da vida acabando. A esse respeito, Ricœur (1990a, p. 314, tradução nossa) afirma que as controvérsias acerca da vida presente no embrião e no feto humano estão centradas na discordância em torno da definição de "que espécie de seres eles são, se não são nem coisas,

22 Do original: Dans tels cas, il faut peut-être avoir compassion pour des êtres trop faibles moralement et physiquement pour entendre la vérité. 
nem pessoas". ${ }^{23}$ Esse caso encontra-se em um âmbito de discussão que põe em xeque a dicotomia desse paradigma ético-ontológico. Tanto no que concerne a um embrião no útero quanto a um embrião de proveta, concebido em laboratório, apresenta-se um conflito que tem seu cerne no conceito de pessoa humana. Se, por um lado, o embrião e o feto forem considerados humanos, eles serão universalizados, isto é, passarão a fazer parte da humanidade e a gozar dos direitos humanos. Do contrário, a instrumentalização de ambos poderia ser autorizada?

Nesse contexto, para que seja possível considerar quais são as possíveis contribuições da sabedoria prática, será preciso transitar entre duas teses distintas: a biológica e a da autonomia. De acordo com a primeira, deve-se interditar toda prática que não esteja em conformidade com os fins pressupostos tanto para o embrião quanto para o feto, quais sejam, viver e atingir seu pleno desenvolvimento. Nesse caso, avalia o pensador francês, "pessoa e vida são indissociáveis, uma vez que esta sustenta aquela: ora, diz o argumento, o patrimônio genético ou genoma que distingue a individualidade biológica é constituído desde a concepção" (RICEUR 1990a, p. 314, tradução nossa) ${ }^{24}$. Por sua vez, a tese que se sustenta na autonomia da vontade implica em considerar que apenas adultos, com suas capacidades plenamente desenvolvidas, é que possuem dignidade humana. Quanto aos demais, a comunidade de "pessoas esclarecidas" é que pode decidir se irá protegê-los. Proteger distingue-se fundamentalmente de respeitar. $\mathrm{O}$ respeito remete-se à autonomia, ao passo que a proteção é o que se pode oferecer aos grupos de pessoas incapazes de um mínimo de autonomia.

Uma interface entre as teses supracitadas verifica-se na possibilidade de uma ontologia mínima de desenvolvimento (RICFUR, 1990a). Tratar-se-ia de uma ontologia progressiva, que consideraria o ser hu-

\footnotetext{
23 Do original: Quelle sorte d'êtres ils sont, s'ils ne sont ni choses, ni personnes.

24 Do original: Personne et vie sont indissociables, dans la mesure où celle-ci ètaye celle-lá: or, dit l'argument, le patrimoine génétique ou génome qui signe l'individualité biologique est constitué dès la conception.
} 
mano "em potencial". Isso implicaria em um permanente respeito ao ser humano; porém, em diferentes níveis, de acordo com seu estágio de desenvolvimento. Entretanto, a dicotomia seria mantida, na medida em que subsistiria a distinção entre maneira de ser e maneira de tratar o ser. Para o filósofo francês,

o teor ontológico atribuído ao predicado "potencial", na expressão "pessoa humana potencial", talvez não seja separável da maneira de "tratar" os seres, correspondente a esses diversos estádios. Maneira de ser e maneira de tratar parecem precisar determinar-se conjuntamente na formação dos juízos prudenciais suscitados por cada avanço do poder que a técnica hoje propicia sobre a vida em seus primórdios (RICEUR, 2014, p. 316).

As deliberações oriundas do julgamento prudencial encontram-se nos domínios da bioética (RICCEUR, 1990a; MORATALLA, 2007). A bioética introduz o debate acerca do "jogo complexo entre ciência e sabedoria [em que] a avaliação dos riscos incorridos com relação às gerações futuras não pode deixar de moderar as audácias que as proezas técnicas encorajam" (RICEUR, 1990a, p. 317, tradução nossa) ${ }^{25}$. Disso resulta que a reflexão concernente ao direito à vida dos embriões e dos fetos encontra-se no âmbito da sabedoria prática "exigida pelas situações conflituais oriundas do próprio respeito num campo em que a dicotomia entre pessoa e coisa é posta em xeque" (RICCEUR, 1990a, p. 317, tradução nossa) ${ }^{26}$.

A sabedoria prática circunscreve-se a três pontos fundamentais: 0 princípio do respeito kantiano, da justa medida aristotélica e a convicção, a qual, por sua vez, deve sempre vir acompanhada da opinião de outros

\footnotetext{
25 Do original: Dans ce jeu complexe entre science et sagesse, la pesée des risques encourus à l'égard des générations futures ne peut manquer de tempérer les audaces que les prouesses techniques encouragent.

${ }^{26}$ Do original: Requise par les situations conflictuelles issues du respect lui-même dans un domaine où la dichotomie entre personne et chose est mise en déroute.
} 
antes de confirmar uma decisão. Porém, não se trata de uma opinião qualquer, mas daquela oriunda do aconselhamento e do diálogo com os mais sábios e esclarecidos dentre os homens e as mulheres. Em outras palavras, "o phronimos não é necessariamente um homem só" (RICEUUR, 1990a, p. 318, tradução nossa, grifo do autor) ${ }^{27}$. Ademais, a decisão oriunda dos três pontos mencionados acima

está longe de ser mecânica, linear e automática [...]. Temos um misto de interpretação e compreensão: o primeiro vocábulo designa o lado lógico (dedução ou indução), e o segundo enfatiza a inventividade, a originalidade, a criatividade. Este misto merece ser chamado de aplicação: aplicar uma regra para um caso ou encontrar uma regra para um caso é produzir sentido (RICEUUR, 2008, p. 245).

A produção de sentido é o principal contributo da sabedoria prática para a solicitude - o tornar-se próximo -, uma vez que a primazia nas decisões não é concedida à lei, e sim à alteridade do ser humano. Ocorre aqui uma inovação ética, que vai além do mero consenso. Trata-se de uma evolução que permite novas soluções capazes de fazer convergir opiniões que, em princípio, eram divergentes (RICEUUR; CHANGEX, 1998; MORATALLA, 2007).

\section{Considerações finais}

A bioética - especialmente quando trata dos hard cases - nos impele a tomar partido, ou seja, entrar em zonas de conflito, sobretudo por conta da norma moral que intenciona estabelecer padrões universais, por vezes desconsiderando os casos singulares. Contudo, Ricœur entende que não é preciso temer o conflito, porque ele é intrínseco à natureza das ações humanas. Sendo assim, não adianta sonhar com uma paz perpétua porque, quanto mais complexa se torna uma sociedade, mais os conflitos tendem a se multiplicar.

27 Do original: Le phronimos n'est pas forcément un homme seul. 
Então, de que forma será possível buscar soluções para tais conflitos? Por meio da sabedoria prática. Esta, por sua vez, não se sobrepõe como um conhecimento infalível, válido universalmente para todos e para sempre. Trata-se de buscar uma resposta que se ajuste mais adequadamente à singularidade de cada caso, fazendo justiça à realidade em sua complexidade, o que não implica em garantia de acerto e eliminação do sofrimento: no que concerne aos casos difíceis, o sofrimento é inevitável.

A intenção da bioética, nas suas múltiplas abordagens, é refletir, por meio de argumentos sólidos, as dificuldades e implicações morais para tornar "o próximo" um sujeito de respeito prudencial, a fim de garantir sua alteridade. $\mathrm{O}$ outro como diferente, mas assegurado em suas plenas condições de exercer a autonomia de escolha, principalmente no momento do sofrimento. Por isso, a verdade necessita de dosimetria comunicacional adequada, considerando, em primeiro lugar, a fenece do sujeito e sua dor.

O sofrimento humano, como experiência fundamental para a clínica, possui também fronteiras filosóficas. O desejo de ser deve superar a "desestima de si", à luz da produção de sentido. Embora essa condição possa mostrar-se frágil, ao seu modo, busca ampliar o horizonte interpretativo da ética e da bioética, não impondo verdades absolutas e prontas às situações de conflito moral. Sua aplicação dar-se-á no diálogo plural e interdisciplinar por meio do envolvimento reflexivo de atores preocupados com a consciência moral de todos os seres humanos.

\section{Referências}

ARISTÓTELES. Ética a Nicômaco. Tradução de Leonel Vallandro e Gerd Bornheim. São Paulo: Abril Cultural, 1984.

BEAUCHAMP, T. L.; CHILDRESS, J. F. Principles of Biomedical Ethics. 7. ed. New York: Oxford University Press, 2012.

DA RE, A. L'aspirazione alla 'vita buona'. In: DANESE, A. (org.). L'io dell'altro: confronto con Paul Ricœur. Genova: Marietti, 1993. p. 215-226. 
DOPPENSCHMITT, M. S. K. V. A bioética clínica de Ricœur. 2015. Tese (Doutorado em Filosofia) - Universidade de São Paulo, São Paulo, 2015. Disponível em: http://www.teses.usp.br/teses/disponiveis/8/8133/tde04122015-135731/pt-br.php. Acesso em: 15 ago. 2018.

ENGELHARDT, H. T. A skeptical reassessment of bioethics. Philosophy and Medicine, [S. l.], v. 100, p. 1-28, 2012. https://doi.org/10.1007/978-94-0072244-6 1

ENGELHARDT, H. T. Fundamentos da bioética. 5. ed. São Paulo: Edições Loyola, 2013.

FRANKENA, W. Ética. Rio de Janeiro: Zahar editores, 1981.

HANSON, S. S. Justifying moral claims in a pluralistic society. Philosophy and Medicine, [S. l.], v. 103, p. 1-14, 2009. https://doi.org/10.1007/978-90-4812508-1_1

HOTTOIS, G. Defining Bioethics: back to the sources. In: MEACHAM, D. Medicine and society, new perspectives in continental philosophy. Bristol: springer, 2015. p. 15-38. https://doi.org/10.1007/978-94-017-9870-9_2

JENNINGS, B (ed.). Bioethics. 4. ed. USA: Wadsworth Publishing Co Inc, 2014. JAHR, F. Bio-Ethik. Eine Umschau über die ethischen Beziehungen des Menschen zu Tier und Pflanze. Kosmos: Handweiser für Naturfreunde, v. 24, n. 1, p. 2-4, 1927.

JONSEN, A. R. The Birth of Bioethics. New York: Oxford University Press, 1998. KANT, I. Fundamentação da metafísica dos costumes. Tradução de Paulo Quintela. Lisboa: Edições 70, 2007.

LECOMTE, J. Connaissance de soi et éthique de l'action: rencontre avec Paul Ricœur. Entrevistado: Paul Ricœur. Sciences Humaines, n. 63, 1996. Disponível em: http://www.fondsricoeur.fr/uploads/medias/articles_pr/connaissance-de-soi.pdf. Acesso em: 20 ago. 2018.

MARCEL, G. Être et Avoir. Paris: Aubier, 1935.

MERLO, P. Fondamenti \& temi di bioética. 2. ed. Roma: LAS, 2011.

MORATALLA, T. D. Bioética y hermenêutica: la aportación de Paul Ricœur a la bioética. Veritas: Revista de Filosofia y Teología, Porto Alegre, v. 2, n. 17, p. 281-312, 2007.

MUZUR, A.; SASS, H. M. (ed.). Fritz Jahr and the foundations of global bioethics: the future of integrative bioethics. Berlim: Lit Verlag, 2012. 
MUZUR, A.; SASS, H. M (ed.). 1926-2016 Fritz Jahr's Bioethics: A global Discourse. Berlin: Lit Verlag, 2017.

MULLER, J-M.; VAILLANT, F. Pour une éthique du compromis. Entrevistado: Paul Ricœur. Alternatives Non-Violentes. n. 80, 1991. Disponível em: http:// www.fondsricoeur.fr/uploads/medias/articles_pr/pour-une-ethique-du-compromis.pdf. Acesso em: 23 ago. 2018.

PESSINI, L.; SGANZERLA, A.; ZANELLA, D. Van Rensselaer Potter: um bioeticista original. São Paulo: Edições Loyola, 2018.

POTTER, V. R. Bioethics: bridge to the future. Englewood Cliffs: PrinticeHall, 1971.

POTTER, V. R. Global Bioethics: Building on the Leopold Legacy. East Lansing: Michigan State University Press, 1988.

POTTER, V. R. Bioethics: the Science of survival. Perspectives in biology and Medicine, [S. l.], v. 14, p. 120-153, 1970. https://doi.org/10.1353/pbm.1970.0015

REICH, W. T. Encyclopedia of bioethics. 2. ed. New York: Macmillan, 1995.

RICEUR, P. O si mesmo como outro. Tradução de Ivone C. Benedetti. São Paulo: Martins Fontes, 2014.

RICEUUR, P. La souffrance n'est pas la douleur. In: MARIN, C.; ZACCAÏ-REYNERS, N. Souffrance et douleur. Autour de Paul Ricœur. Paris: Presses Universitaires de France, 2013. p. 13-34. https://doi.org/10.3917/puf.marin.2013.01.0013

RICCEUR, P. Ética e moral. Tradução de Antonio C. Amaral. Covilhã: LusoSofia, 2011. Disponível em: http://www.lusosofia.net/textos/ricoeur paul etica_e_moral_rpf1990.pdf. Acesso em: 20 ago. 2018.

RICEUR, P. O justo 2: justiça e verdade e outros estudos. Tradução de Ivone C. Benedetti. São Paulo: Martins Fontes, 2008.

RICCEUR, P. La mémoire, l'histoire, l'oublie. Paris: Seuil, 2000.

RICEUR, P. De la métaphysique à la morale. Revue de Métaphysique et de Morale, [S. l.], v. 98, n. 4, p. 455-477, 1993.

RICEUR, P. Lectures 1: autour du politique. Paris: Seuil, 1991.

RICEUR, P. Soi-même comme un autre. Paris: Seuil, $1990 a$.

RICCEUR, P. Ethique et morale. Revista Portuguesa de Filosofia, Braga, v. 46, n. 1, p. 5-17, 199ob. 
RICEUUR, P. Du texte à l'action: essais d'herméneutique II. Paris: Seuil, 1986. https://doi.org/10.14375/NP.9782020093774

RICEUR, P. The Problem of the Foundation of Moral Philosophy. Philosophy Today, [S. l.], v. 22, n. 3, p. 175-192, 1978. https://doi.org/10.5840/philtoday197822310

RICEUR, P. Histoire et vérité. Paris: Seuil, 1955.

RICEUR, P. Sympathie et respect: phénoménologie et éthique de la seconde personne. Revue de Métaphysique et de Morale, [S. I.], v. 59, n. 4, p. 380-397, 1954.

RICEUR, P.; CHANGEUX, J. P. La naturaleza y la norma: lo que nos hace pensar. México: Fondo de Cultura Económica, 2001.

RICCEUR, P.; CHANGEUX, J. P. La nature et la règle: ce qui nous fait penser. Paris: Editions Odile Jacob, 1998.

PELICIER, Y.; RICCEUR, P. A ética, entre o mal e o pior. 1994. Registro de Christian Ballouard e Sophie Duméry. Disponível em: http://www.uc.pt/fluc/ lif/publicacoes/textos disponiveis online/pdf/entrevista_yves_pelicier. Acesso em: 14 jul. 2018.

ROSSATTO, N. D. A ética de Paul Ricœur. In: SILVEIRA, D. C.; HOBUSS, J. (org.). Virtudes, direitos e democracia. Pelotas: Editora Universitária UFPel, 2010. p. 45-60.

ROSSATTO, N. D. Viver bem. Mente, Cérebro e Filosofia, São Paulo, n. 11, p. 26-33, 2008.

SASS, H. M. Fritz Jahr's 1927 Concept of Bioethics. Kennedy Institute of Ethics Journal, v. 17, n. 4, p. 279-295, 2008. https://doi.org/10.1353/ken.2008.0006 SÓFOCLES. Antígona. Tradução de Donaldo Schüler. Porto Alegre: L\&PM, 2011.

\section{Endereço Postal}

\section{Paulo Gilberto Gubert}

Rua Uruguaiana, 781, Bairro Mathias Velho, Canoas, RS, CEP: 92330-370 